\title{
COAL DESULPHURISATION AND ASH REMOVAL IN INTENSIFIED
} MAGNETIC FIELDS

\author{
A.M. SAEID, D.A. BUTCHER AND N.A. ROWSON \\ School of Chemical Engineering, The University of Birmingham, \\ Edgbaston, Birmingham B15 2TT, England
}

(Received June 16, 1992; Revised August 17, 1992)

\begin{abstract}
Data is presented demonstrating the effect of high gradient/high strength magnetic fields on a UK coal. Experimentation was carried out using a high-intensity (HIW) magnetic separator and coarser coal fractions were treated on a permanent magnetic roll separator capable of producing exceptionally high magnetic field gradients.

Total sulphur and ash removal data is given for coal fractions after magnetic treatment plus X-ray diffraction and magnetic profile analysis provides identification of the mineral constitution of the ash fraction of the coal.
\end{abstract}

\section{INTRODUCTION}

Magnetic separation has been applied to the problem of removing sulphur and ash from coal prior combustion at coal burning power stations. Initial work [1] was carried out using a HIW type canister separator capable of field strengths in the region of $20 \mathrm{kGauss}$ in the open gap of the unit. Reports indicated that it proved possible to capture ash and pyrite in this separator at very low solids concentration and slurry flow rates.

Other workers $[2,3]$ attempted to increase the magnetic susceptibility of very weakly paramagnetic pyrite prior to magnetic separation by treating the coal with microwave energy to facilitate the change of $\mathrm{FeS}_{2} \rightarrow \mathrm{FeS}$ (pyrrhotite). Subsequent 
downstream magnetic processing efficiency is improved due to enhanced magnetic properties of the 'altered' $\mathrm{FeS}_{2}$.

Chemical treatments $[4,5]$ have also been used to increase the composite magnetic susceptibility of the pyrite particles. Caustic $(\mathrm{NaOH})$ leaching can form iron oxide coatings of the pyrite surface thereby rendering it more magnetic.

\section{EXPERIMENTAL STUDIES}

The coal sample used for this experimental work was supplied by British Coal Opencast Division, Stoke, Stafford. It is a high sulphur, medium ash bituminous coal.

Typical approximate analysis for the $-500 \mu \mathrm{m}$ size fraction was as follows:

$\begin{array}{ll}\text { Ash } & 12.2 \% \\ \text { Volatile Matter } & 65.6 \% \\ \text { Fixed carbon + Moisture } & 22.2 \% \\ \text { Total Sulphur } & 3.8 \%\end{array}$

The coal sample was classified into various size ranges prior to processing on the magnetic separators. Material below $500 \mu \mathrm{m}$ was designated for treatment on the HIW magnetic separator. Further sub-sizing gave three fractions $(-500+300 \mu \mathrm{m}$, $-300+106 \mu \mathrm{m},-106 \mu \mathrm{m})$ for analysis.

Coarse particles were suitable for treatment on the dry roll separator. Again, these were classified to give a close size fraction passing over the unit.

The equipment used was a Boxmag-Rapid HIW laboratory high-intensity wet magnetic separator capable of $0-14 \mathrm{kG}$ in the open gap of the separator (Figure 1). A mild steel matrix (expanded metal) was inserted into the separator to capture ash/pyrite when the electromagnet is energised. Solids were passed through the unit in a $20 \%$ wt suspension. Paramagnetic particles are held on the energised matrix whilst the diamagnetic particles pass through unaffected and exit via the bottom of the canister. At the end of the cycle the magnet is de-energised and the magnetics are washed free. 


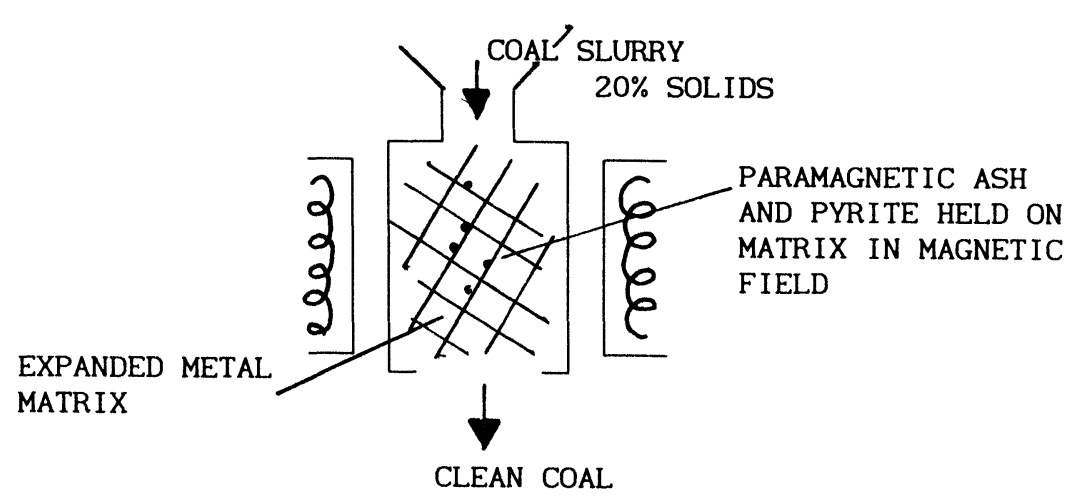

FIGURE 1 Operation of wet magnetic separator

The coarse coal particles were processed over a Boxmag-Rapid Magnaroll separator (Figure 2). This high-strength (10 kGauss)/high-field gradient roll separator utilises neodymium-iron-boron magnetic material to give excellent separation performance at a larger particle size range.

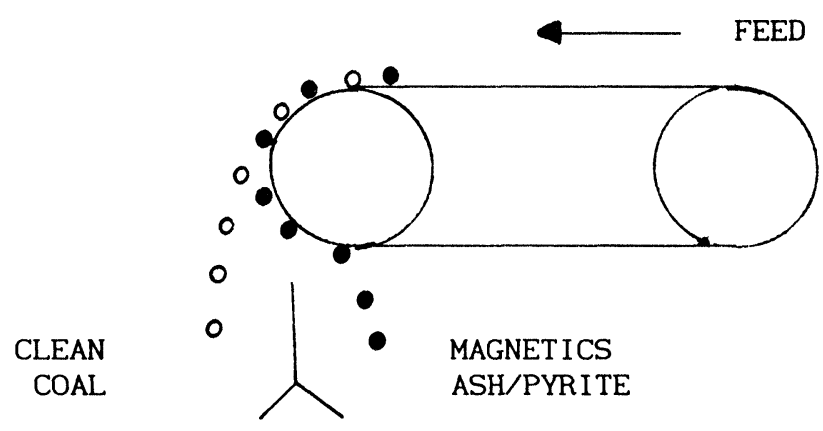

FIGURE 2 Operation of a permanent magnetic roll separator

The coal fractions were sized and fed via a vibratory feeder onto the belt of the roll separator. The weakly paramagnetic minerals (ash/pyrite) are deflected by the influence of the magnetic roll, whilst the non-magnetics (coal) are thrown from the separator by the centrifugal force induced by the revolving roll.

The separation of magnetics from non-magnetics can be controlled by the 
adjustable splitter plate and varying the belt speed of the unit.

\section{WET MAGNETIC SEPARATION RESULTS}

Analysis of the magnetic and non-magnetic products from these tests showed various trends. The field strength of the separator was adjusted between 8 and 14 kGauss.

Figure 3 illustrates the ash removal from the coal feed with variation of particle size at an applied field of $8 \mathrm{kGauss}$. The magnetic product has an ash content of $47 \%$, whilst the ash content of the feed has been reduced by up to $25 \%$ for some of the test trials.

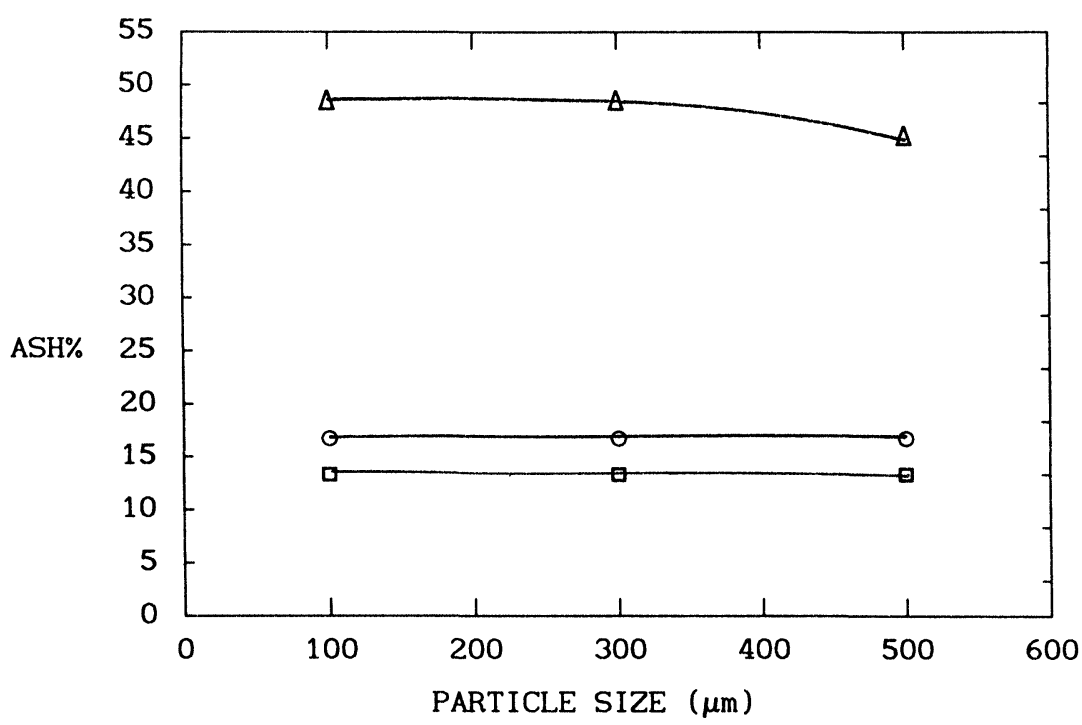

FIGURE 3 Variation of ash content with particle size of feed

Wet magnetic separation trial: 8 kGauss
$\triangle$ ASH $\%$ OF MAGS.
口 ASH \% OF NON- MAGS.
○ ASH \% OF FEED 
Increasing the magnetic field intensity in the open gap of the separator did not significantly affect the ash removal from the coal (Figure 4).

The total sulphur analysis did not reveal any consistent removal of sulphur from the non-magnetic fraction during the high-intensity wet magnetic separation tests.

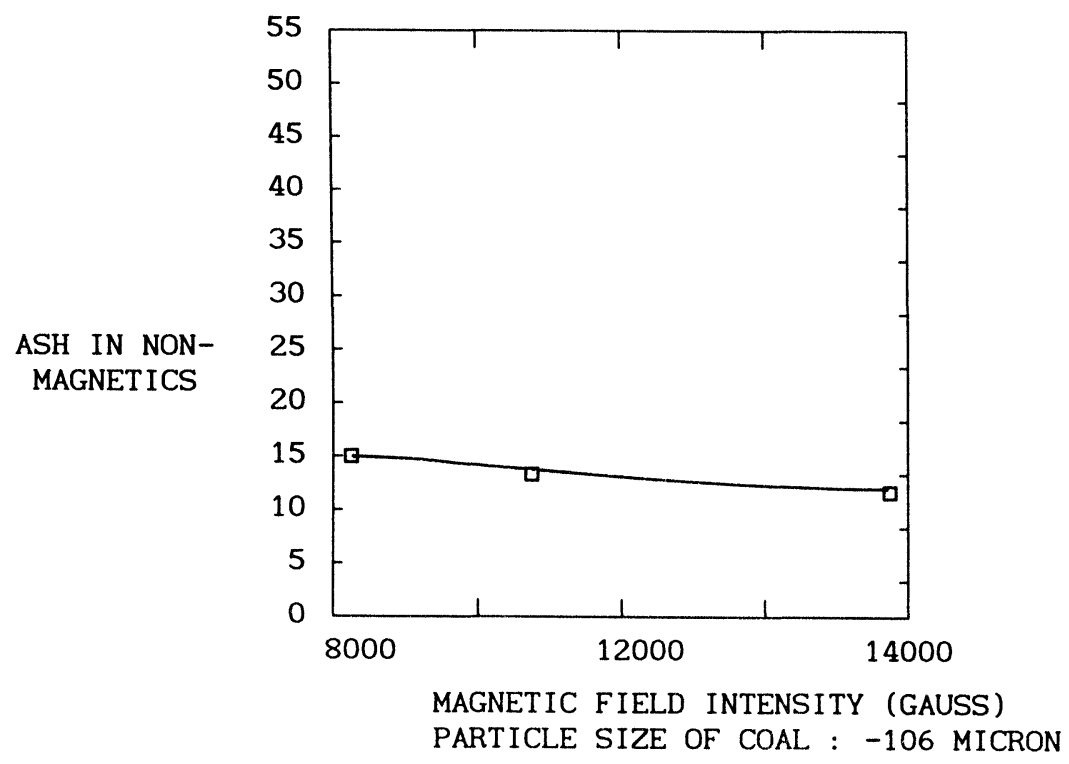

FIGURE 4 Effect of magnetic field intensity on ash content in non-magnetics

\section{DRY MAGNETIC SEPARATION}

The permanent roll type separator was capable of processing coal samples up to 5 mm particle size.

The ash analysis of processed samples (Figure 5) demonstrated a significant ash reduction at lower ranges $(-2 \mathrm{~mm})$, with a $40 \%$ reduction in the $-500+106 \mu \mathrm{m}$ size fraction being achieved. The magnetics from this size range contained $47 \%$ ash. 
Total sulphur removal results confirmed a reduction in sulphur (Figure 6) across the complete size range of coal processed. The degree of sulphur reduction was, however, slightly disappointing with approximately $10 \%$ of the sulphur being removed in the small size range fractions.

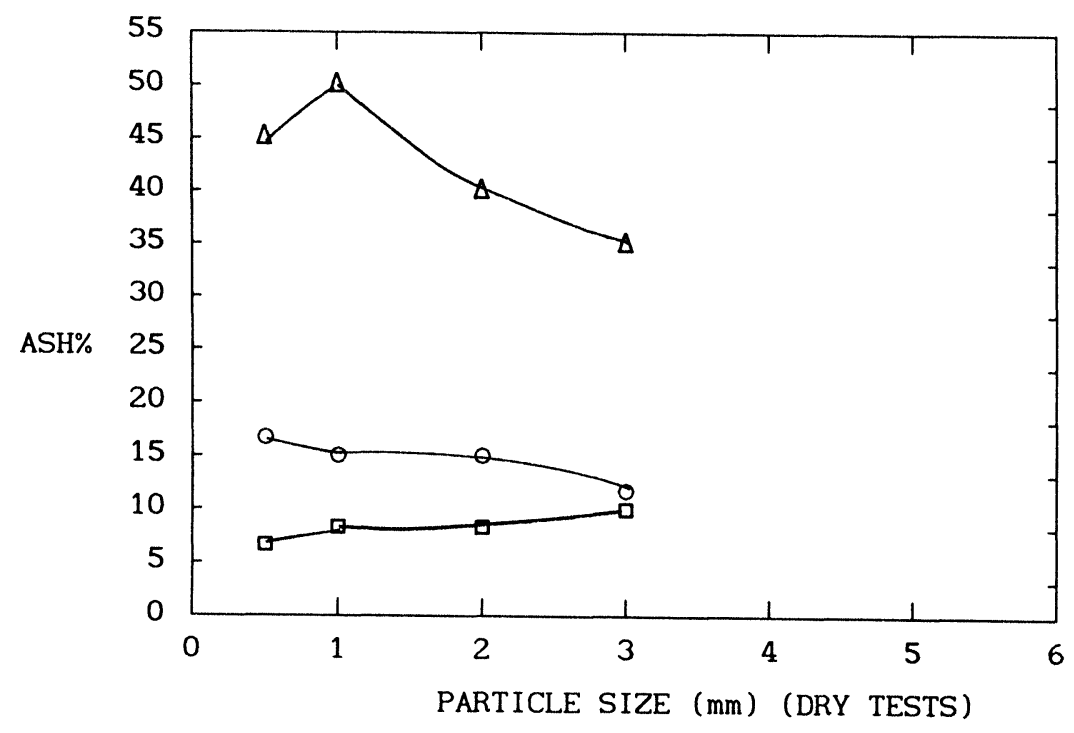
FIGURE 5 Ash content of coal after processing $\bigcirc$ ASH OF THE FEED
$\triangle \mathrm{ASH} \%$ OF MAGNETICS 口 ASH \% OF NON- MAGNETICS

The total sulphur results were confirmed with pyritic sulphur analysis which again demonstrated that pyrite was being concentrated in the magnetic fraction from the dry roll tests.

\section{ANALYTICAL DATA}

The proximate analysis of coal was carried out to BS.1016 part 3. Reproducibility was within this specified in BS.1016 (ash $0.4 \%$, volatile matter $1.0 \%$ absolute).

Total sulphur determinations were carried out using Escheka sulphur analysis BS.1016 part 2 and Leco total sulphur determination equipment. 


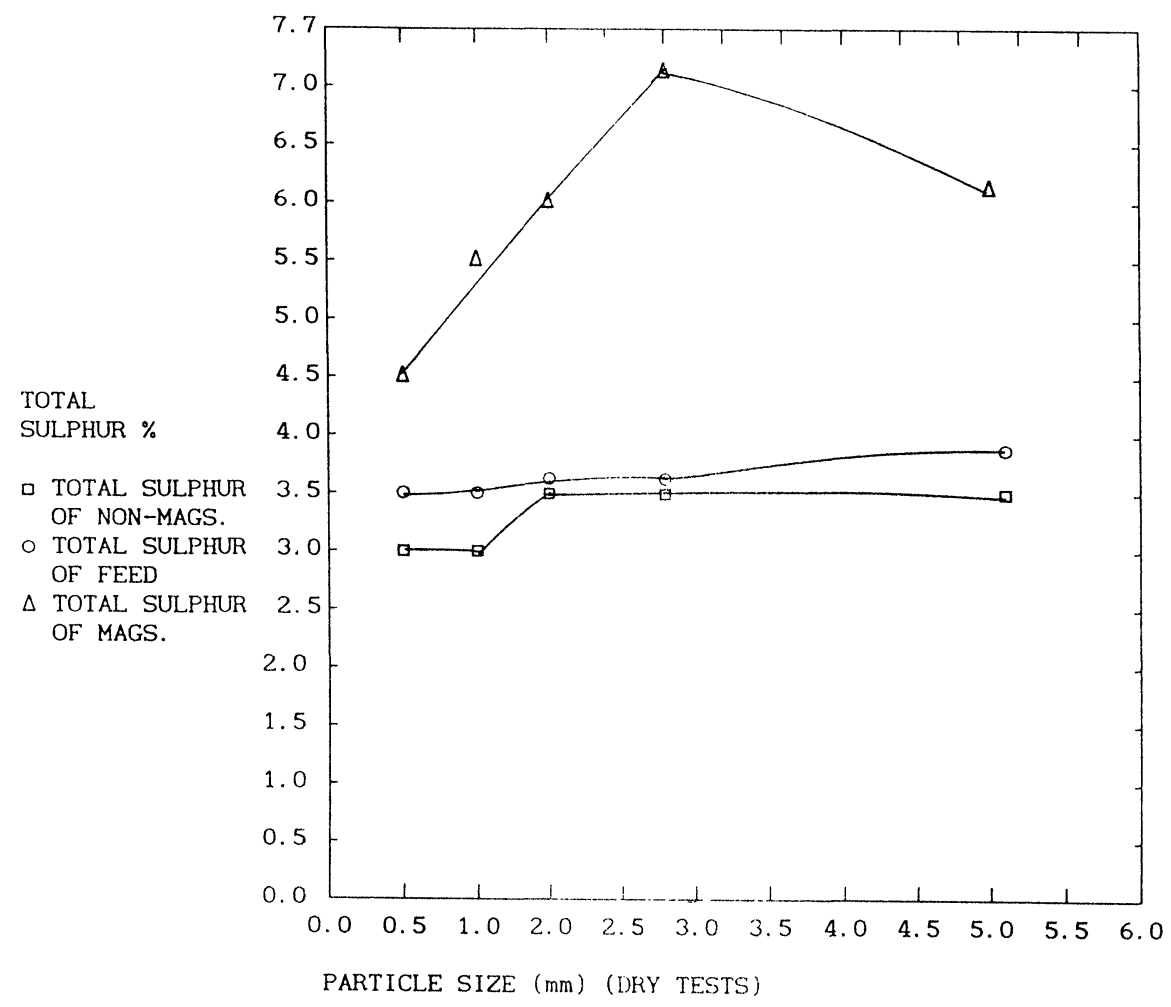

FIGURE 6 Total sulphur \% removal after magnetic separation

Magnetic characterisation analysis of pyrite (Figure 7) shows its very weak paramagnetic properties. There is no perceptible increase in magnetic susceptibility when an external magnetic field is applied.

In contrast, the magnetic profile analysis of the coal magnetics for the dry separation tests (Figure 8) demonstrates a moderate magnetic susceptibility enabling it to be removed from diamagnetic organic coal during processing.

Therefore, there must be other minerals within the ash content of the coal which account for the difference in magnetic properties between pyrite and coal ash.

$\mathrm{X}$-ray diffraction analysis was utilised to ascertain a mineral identification of the coal magnetic fraction from the dry tests. The ash contained pure pyrite, quartz and ferroan dolomite (calcium magnesium iron carbonate). It is the presence of 
ferroan dolomite which accounts for the magnetic properties of this particular coal ash.

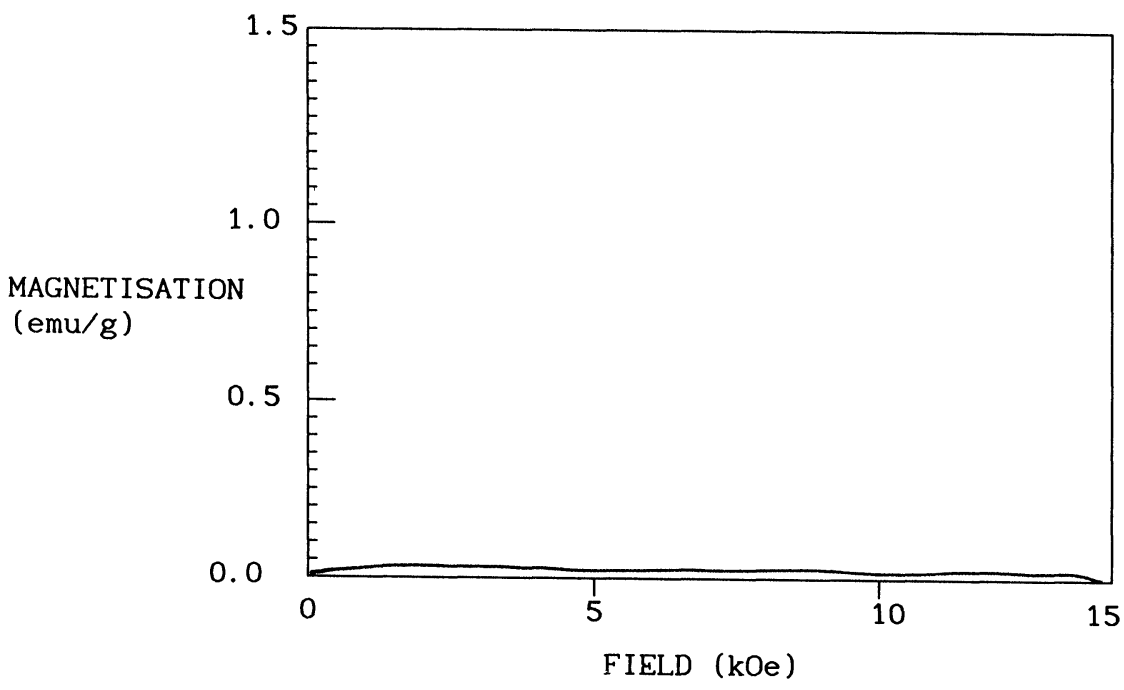

$$
\begin{array}{llll}
\text { SAMPLE } & : & \text { PYRITE } \\
\text { FORMULA } & : & \mathrm{FeS}_{2} & \\
\text { SUSCEPTIBILITY } & : & <6.0 & 10^{-6} \quad(\mathrm{emu})
\end{array}
$$

FIGURE 7 Magnetic characterisation of pyrite

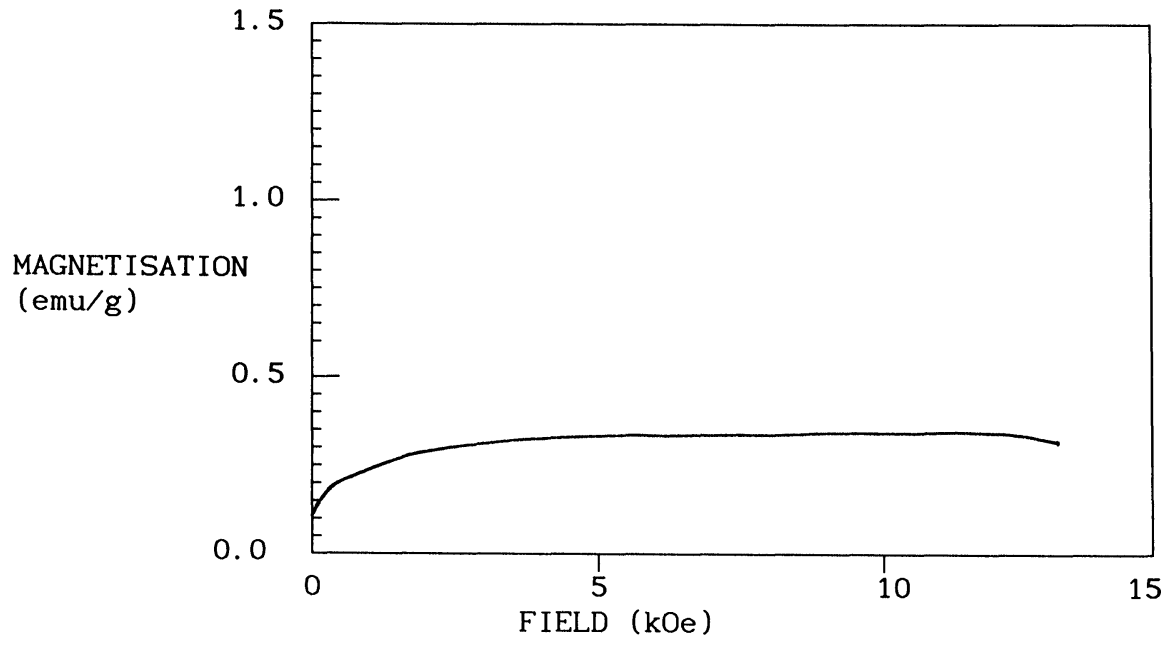

SAMPLE $\quad: \quad$ COAL MAGNETICS (ASH AND PYRITE)

FIGURE 8 Magnetic characterisation of coal magnetics 
Petrological examination of the coal revealed that the ash tends to associate with discreet particles of pyrite. The organic coal macerals themselves are relatively free from pyrite inclusions.

\section{$\underline{\text { SUMMARY }}$}

The high-intensity wet magnetic separation trials proved successful at reducing the ash content of the coal by a maximum of $25 \%$ after one pass through the separator. This gave a concentrated magnetics fraction containing $45-50 \%$ ash. However, no advantage was demonstrated in increasing the magnetic field applied above 8 kGauss. Sulphur removal during these tests was not observed on a consistent level across the $-500 \mu \mathrm{m}$ size ranges.

The dry magnetic separation trials removed both ash and sulphur from the coal. Ash removal was maximised at $40 \%$ for the $-500+106 \mu \mathrm{m}$ coal fraction, with total sulphur removal being in the order of $10 \%$.

The absence of sulphur removal during wet test trials may be explained by the petrological nature of the coal. The ash and pyrite associate together, the finer size fractions being processed through the wet separator cause the liberation of the pyrite from the ash. Therefore, only the ash is removed during wet testing, the liberated pyrite itself does not have a large enough magnetic susceptibility to be removed.

Further work is now being carried out to optimise this dry separation using different magnetic roll configurations and also bacterial magnetic enhancement experimentation is being attempted to improve the magnetic properties of the pyrite.

\section{ACKNOWLEDGMENT}

The authors gratefully acknowledge the financial and technical assistance from British Coal, Bretby for D.A. Butcher and the Libyan Government for A.M. Saeid. 


\section{REFERENCES}

1. H.H. Holm: Fuel 53, 177 (1974)

2. P.D. Zavitsanos: US Patent Application 4,076,607 (1975)

3. P.D. Zavitsanos: Coal desulphurisation by a microwave process. DOE/DP/30142/T4 (1982)

4. N.A. Rowson and N.M. Rice: Min. Eng. 3, 355 (1990)

5. S. Hall, J. Finch and N. Rowlands: Trans. Inst. Min., Metal. 94, C35 (1985)

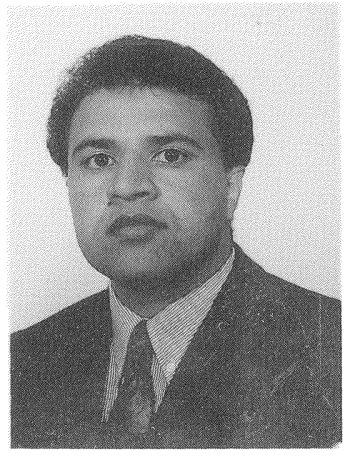

Abdolkarib Mohamad Saeid graduated from the Chemical Engineering Department, Bright Star University, Libya. He worked as assistant lecturer at Al-Fateh University, Tripolia, between 1986 and 1989. He came to the UK in 1989 to complete his M.Sc. degree in the Chemical Engineering Department at Imperial College, London, before starting a Ph.D. in the School of Chemical Engineering at the University of Birmingham in 1991.

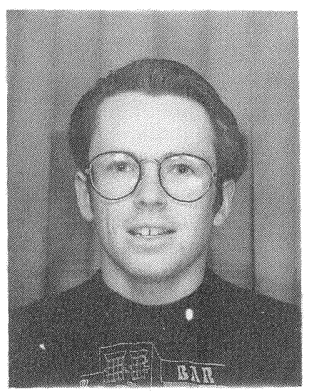

David Butcher graduated from the School of Chemical Engineering at the University of Birmingham in 1991. $\mathrm{He}$ is currently completing his Ph.D. studies in the removal of pyrite from coal in intensified magnetic, electrostatic and gravitational fields.

N.A. Rowson: for biography see Mag. El. Sep. 3 (1992), 105

Keywords: coal cleaning, magnetic separation, desulphurisation. 